$\begin{array}{ll} & \text { Etnográfica } \\ \text { etnográfica } & \text { Revista do Centro em Rede de Investigação em }\end{array}$

Antropologia

vol. $13(1) \mid 2009$

Vol. $13(1)$

\title{
Manuela Palmeirim, of Alien Kings and Perpetual Kin: Contradiction and Ambiguity in Ruwund (Lunda) Symbolic Thought
}

\section{Ramon Sarró}

\section{(2) OpenEdition}

\section{Journals}

\section{Edição electrónica}

URL: https://journals.openedition.org/etnografica/1279

DOI: 10.4000/etnografica.1279

ISSN: 2182-2891

\section{Editora}

Centro em Rede de Investigação em Antropologia

Edição impressa

Data de publição: 2 maio 2009

Paginação: 225-226

ISSN: 0873-6561

\section{Refêrencia eletrónica}

Ramon Sarró, «Manuela Palmeirim, Of Alien Kings and Perpetual Kin: Contradiction and Ambiguity in Ruwund (Lunda) Symbolic Thought», Etnográfica [Online], vol. 13 (1) | 2009, posto online no dia 29 março 2012, consultado o 11 fevereiro 2022. URL: http://journals.openedition.org/etnografica/1279; DOI: https://doi.org/10.4000/etnografica.1279

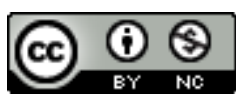

Etnográfica is licensed under a Creative Commons Attribution-NonCommercial 4.0 International License. 
Manuela Palmeirim

OF ALIEN KINGS AND PERPETUAL KIN: CONTRADICTION AND AMBIGUITY IN RUWUND (LUNDA) SYMBOLIC THOUGHT

Wantage (Oxon), Sean Kingston Publishing, 2006, 175 páginas.

Não deixa de ser interessante que tenha sido no ano do centenário de Lévi-Strauss que tive oportunidade de ler esta obra. O esforço mitológico que este autor realizou na América teve pouco eco em África. Com poucas excepções, entre as quais a mais significativa é sem dúvida a do antropólogo belga L. De Heusch, poucos autores se dedicaram a estudar o mito em África como Lévi-Strauss o fizera na América. Para tornar mais complicada a recepção do estudo estrutural do mito em contextos africanos, o trabalho de De Heusch despertou um debate, por vezes visceral, com o seu conterrâneo historiador J. Vanisa, para quem os exercícios estruturalistas de De Heusch representavam um obstáculo para o estudo do valor histórico das tradições orais.

Manuela Palmeirim toma partido pela visão estruturalista, na qual o valor do mito de origem e dos heróis culturais radica na sua capacidade de oferecer um modelo através do qual a sociedade se pensa a si própria. $\mathrm{O}$ livro trata do mito de criação dos Aruwund e do poder legitimador que o mito confere ao seu rei, o Mwant Yaav. Os Aruwund vivem no Sul da República Democrática do Congo (ex-Zaire), onde a autora realizou trabalho de campo em 1987-88 e em 1992 quando realizava a sua tese de doutoramento em antropologia na School of Oriental and African Studies de Londres. Como outros povos centro-africanos, os Aruwund, hoje habitantes da província de Katanga, apresentam um modelo de realeza divina no qual o rei é fundamental para o bem-estar da terra e da comunidade, embora coexista com outros mecanismos de poder governamental dependentes de Kinshasa. O estudo de Palmeirim é importante não só porque constitui uma análise muito detalhada do pensamento simbólico, mas também porque Katanga, com uma história marcada por episódios e reivindicações independentistas, é uma região muito problemática no contexto de um país cuja estrutura territorial é particularmente volátil.

O livro não só oferece um exemplo paradigmático de análise estruturalista aplicada à realeza divina, como é também uma excelente introdução ao debate sobre o mito e a história que atravessa a literatura historiográfica e antropológica africanista dos últimos 50 anos, sobretudo no capítulo 2 . Aqui a autora debruça-se sobre os heróis que articulam a memória dos dignitários reais em torno de Mwant Yaav, exercício que revitaliza o clássico tema do culture heroe (neste caso, um caçador) e da invenção 
da civilização, uma temática anteriormente analisada, na mesma região, por De Heusch, com quem a autora mantém um constante diálogo e também algumas discrepâncias interpretativas.

Para além dos temas míticos e metodológicos, o trabalho mostra o grande valor analítico que tiveram no passado (e que a autora re-actualiza no presente) os modelos culturais, ligados ao parentesco, do perpetual kinship, segundo I. Cunnison (o modelo segundo o qual os grupos sociais mantêm uma relação de parentesco baseada em relações entre indivíduos de gerações passadas) e da positional succession, segundo A. I. Richards (o modelo onde o antepassado falecido é substituído por uma outra pessoa que ocupa o seu lugar e, como tal, torna irrelevante a sua morte). O conhecimento destes modelos, presentes no pensamento simbólico e na cultura política dos povos centro-africanos, ajuda a análise das situações políticas contemporâneas, em concreto o paradoxo do rei (o centro do livro): o paradoxo segundo o qual o rei é um de nós e ao mesmo tempo um estrangeiro.

A opção por considerar o mito e as suas variações (todas igualmente válidas segundo Lévi-Strauss) como modelos para pensar e não conjuntos de dados factuais sobre a história, leva a autora (capítulo 4) a introduzir um breve e penetrante ensaio sobre a hierarquia. Na sua opinião, a distinção entre "hierarquia" e "igualitarismo" não separa ideologias de diferentes tipos de sociedade, como L. Dumont argumentara. Esses são, sim, modelos complementares que uma mesma sociedade pode invocar, por vezes de forma simultânea e usando diferentes recursos (autoctonia e invasão, para citar dois exemplos contraditórios), para explicar a sua história e produzir o que a autora denomina um "efeito caleidoscópico" pelo qual a hierarquia e a igualdade são ambas importantes para a constituição da realeza (p. 88).
O livro, assim como a pesquisa etnográfica sobre o qual se constrói, apresenta um grande rigor, detalhe e honestidade científica. Embora a síntese seja sempre bem-vinda, neste caso talvez a autora tenha sido demasiado breve na contextualização dos Aruwund no Zaire pós-colonial e se precipite na análise do mito e das suas variações e transformações. Na minha opinião, o principal problema de um estudo simbólico deste tipo é torná-lo relevante para a compreensão da actual política africana (embora pense que, precisamente, devia ser mais relevante). Com a situação no Congo e com os debates científicos em torno do crescente valor - como recurso cultural e político - da “autoctonia" numa África neoliberal (pensemos nos trabalhos recentes de Bayart e Geschiere, por exemplo), assim como com o regresso mais ou menos democrático das chamadas "autoridades tradicionais" em quase todos os países do continente, é pena que a autora não tenha aproveitado o seu incomparável conhecimento da sociedade do Katanga (um dos casos em que a “autoctonia” não é uma metáfora mas um discurso real sobre a emergência telúrica dos habitantes) para dialogar com outros autores e tornar o seu fascinante material muito mas relevante para os debates mais recentes. Mas isto é também efeito da sua honestidade intelectual e da fidelidade ao modelo com que construiu a sua narrativa. Talvez o diálogo com outros autores sobre a politização da autoctonia, sobre a revitalização das realezas divinas em África, sobre a descentralização política e sobre outros aspectos em relação aos quais ela terá, certamente, muito a dizer fique para ulteriores pesquisas. Esperemos que assim seja, e que sejam realizadas com o mesmo rigor e detalhe com que realizou o trabalho agora publicado.

\section{Ramon Sarró}

Instituto de Ciências Sociais (UL) 